\title{
High Flow Nasal Oxygen Therapy in Severe Pneumonia of COVID-19
} Jebbar Nourddine ${ }^{1},{ }^{2 *}$, Maaroufi Ayoub ${ }^{1},{ }^{2}$ Elkaissi Jaber ${ }^{1},{ }^{2}$, Diai Abdellatif ${ }^{1},{ }^{2}$, Jbili Nabil ${ }^{1},{ }^{2}$, Bibiche Lotfi ${ }^{1},{ }^{2}$, Laoutid Jaouad $^{1},{ }^{2}$, Kechna Hicham ${ }^{1},{ }^{2}$

\footnotetext{
${ }^{1}$ Anesthesiology \& intensive care department, Moulay Ismail Military Hospital, Meknes, Morocco

${ }^{2}$ Faculty of Medicine, Sidi Mohamed Ben Abdellah University, Fes, Morocco
}

DOI: $10.36347 /$ sjams.2021.v09i03.013

| Received: 19.02.2021 | Accepted: 02.03.2021 | Published: 05.03.2021

*Corresponding author: Jebbar Nourddine

\section{Abstract}

Coronavirus disease 2019 (COVID-19) has quickly spread across the world and is currently a real public health problem. It is the cause of severe respiratory failure which has caused many deaths. Many therapies aimed at correcting respiratory failure have been used, and it appears that hight flow nasal oxygen (HFNO) therapy has gained space compared to other means of ventilator support. We report in this work our experience with the HFNO in our hospital located in Morocco.

Keywords: COVID-19, (HFNO), Coronavirus disease, Oxygen Therapy.

Copyright $\odot 2021$ The Author(s): This is an open-access article distributed under the terms of the Creative Commons Attribution 4.0 International License (CC BY-NC 4.0) which permits unrestricted use, distribution, and reproduction in any medium for non-commercial use provided the original author and source are credited.

\section{INTRODUCTION}

Coronavirus disease 2019 is a potentially fatal infection caused by the novel severe acute respiratory syndrome coronavirus 2 (SARS-COV 2) [1].

A high number of patients with COVID-19 develop severe bilateral viral pneumonia. Many COVID-19 patients evolve to acute respiratory distress syndrome (ARDS), characterized by profound hypoxemia and an associated high mortality rate [2].

High flow nasal oxygen therapy is effective in decreasing the need for endotracheal intubation in patients with acute hypoxemic respiratory failure [3].

\section{MeTHODS}

Our study is a prospective study spanning four months from the $1^{\text {st }}$ September to the $30^{\text {th }}$ December, involving 64 patients who meet the following criteria:

- $\quad$ Age $>30$ years old.

- Confirmed SARS-COV-2 infection of an airway sample using polymerase chain reaction (PCR).

- No previous invasive ventilation or no invasive ventilation use before starting HFNO.

- $\quad$ Peripheral oxyhemoglobin saturation (spo2) $<90 \%$ with a face mask at $151 / \mathrm{min}$.

- Respiratory rate $>30$ cycles per minute.

- $\mathrm{Pao} 2 /$ fio $2<150$.
HFNO was administrated by an optiflow. The flow was started at $601 / \mathrm{min}$ with fio 2 at 0,8 titrated to aim for oxygen saturation at $95 \%$.

The primary endpoint was the proportion of patients with results (weaned from HFNO).

Failure was defined as composite the need for intubation or death on HFNO. Monitoring elements: C reactive protein, spo2, respiratory rate, thoracic chest computed tomography, the need for invasive mechanical ventilation (MV), the length of Intensive Care Unit (ICU) stay and mortality.

Decision to initiate the HFNO is acute nohypercapnic respiratory failure.

\section{RESULTS}

Sixty-four patients were enrolled between September $1^{\text {st }}$ and December $30^{\text {th }} 2020$, admitted to ICU for HFNO.

The median age was 63 years (40-86), 79\% were men (men 51/ women 13). Each patient was under face mask at $15 \mathrm{~L} / \mathrm{min}$ before initiating HFNO.

The ratio of pao2/fio2 was 97 (74-120). Comorbidities were very common: 49/64 (76\%) patients were diabetic, 45/64 (70\%) were hypertensive, 10/64 $(16 \%)$ were obese (body mass index $>30)$. 
Jebbar Nourddine et al; Sch J App Med Sci, Mar, 2021; 9(3): 364-366

All patients were on curative anticoagulation with enoxaparin $1 \mathrm{mg} / \mathrm{kg}$ every 12 hours and received corticosteroids (prednisolone).

Success with HFNO treatment was achieved in $33 / 64(51 \%)$ of patients and who are released from hospital. The mean duration of HFNO was 15 (8-22) days in people treated successfully versus 9 (2-16) days for the rest. The switchover rate to invasive or noinvasive ventilation was 5/64 and 19/64 (8\%, 29\%) respectively, while the mortality rate for HFNO was 7/64 (11\%) Fig-1.

Patients who tested positive on HFNO had oxygen saturation greater than $95 \%$, respiratory rate less than 20 cycles per minute, heart rate less than 90 beats per minute and pao2/fio2 $>300$ after day 4 of HFNO.

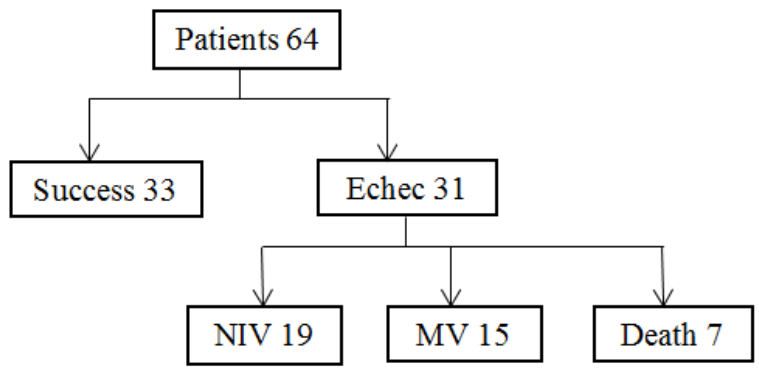

Fig-1: Results of the effect of using HFNO

\section{DiscuSSION}

Optiflow is a high flow nasal oxygen therapy device. Its operation consists on an air-oxygen mixer making it possible to control the Fio2 (up to 100\%) and to generate high flow rates (up to $601 / \mathrm{min}$ ), to deliver controlled oxygen therapy in flow and in inspired fraction, in humidity and heat (via the humidification system of the inspired air as well as a heating base allowing a temperature adjustment to $37^{\circ} \mathrm{C}$ ).

Air and oxygen are thus mixed, warmed, humidified and delivered to the patient via a single branch inspiratory heating circuit through large diameter nasal cannulas.

The physiological effects attributed to the use of this device are numerous:

- Washing of the nasopharyngeal dead space. This results in an increase in the alveolar ventilation to minute ventilation ratio. Several studies performed in mechanical ventilation have shown this effect through the administration of a low flow of oxygen at the end of an intubation tube. Interestingly, high flow oxygen delivery through the nasal cannulas achieves the same effect. Washing the dead space could also have an impact on oxygenation. Chatila and al showed that at equal fio2, high flow versus low flow oxygen therapy allowed COPD (chronic obstructive pulmonary disease) patients to maintain higher oxygenation during exercise. The $\mathrm{PH}$ and the pco2 remained stable with a decrease in the respiratory rate of the patients [4].

- A decrease in inspiratory resistance: the increase in respiratory resistance linked to the retraction of the nasopharynx is attenuated during high flow oxygen therapy

- Respiratory work in spontaneous ventilation is reduced [5].

- Humidification and warming of the inspired gases.

- Improvement of thoraco-abdominal synchronization.

- A positive expiratory pressure (PEP) effect of 1 to $5 \mathrm{cmH} 2 \mathrm{o}$ : few studies have sought to highlights this effect $[6,7]$. The two points raised by these studies were that PEP was only present with the mouth closed and that it depended on the speed used. In healthy volunteers, it increased from $2,9 \mathrm{cmH} 2 \mathrm{o}$ to $7,4 \mathrm{cmH} 2 \mathrm{o}$ between 20 and $60 \mathrm{l} / \mathrm{min}$. the creation of the PEP allows an increase in lung volumes and the functional residual capacity of patients. These different effects are linked to the high flow oxygen rate and the control of fio2. Therefore, the inspiratory flow must be set to the maximum initially and then adjusted secondarily.

The arrival of the OPTIFLOW in our hospital coincided with an increase in the mortality rate in patients with COVID-19 pneumonia, which was around $65 \%$. In fact, the rate of mortality and recourse to noinvasive and mechanical ventilation has considerably decreased.

A study which was published in September 2020 [8] and which was the most important carried out so far on the interest of HFNO and showed that this device can be used successfully to provide respiratory support to these patients with COVID-19 pneumonia and avoid mechanical ventilation even in patients with severe hypoxemia. In addition, the HFNO failed in more than half of the patients $(47 \%$ of success against $53 \%$ of failure). This result attached it to the consequences of a population suffering from socioeconomic difficulties and multiple comorbidities such as tuberculosis.

A second retrospective study [9] carried out in China on the combination of prone position (PP) with HFNO has been published and has objectified that early awakened PP associated with HFNO therapy was the most important strategy to avoid intubation and reduce the need for medical personnel. Early application of PP with HFNO especially in patients with moderate ARDS may help to avoid intubation. The main reasons for complications were: PP intolerance, anxiety and difficulty to change position. Their strategy was psychological by change of position every 2 hours. Compared to NIV, patients felt more comfortable using HFNO therapy and the demand for medical personnel has been reduced. Awake PP combined with HFNO could be used safely and effective in patients with 
Jebbar Nourddine et al; Sch J App Med Sci, Mar, 2021; 9(3): 364-366

severe COVID-19, and it may reduce conversion to serious illness and the need to tracheal intubation.

\section{CONCLUSION}

COVID-19 acute respiratory distress syndrome has become a very common resuscitation problem around the world. The HFNO has earned its place in the treatment of severe case of this pandemic by reducing the need for NIV and MV.

Competing interests: The authors declare no competing interest.

Author's Contributions: All authors have participated equally in the preparation of published manuscript.

\section{Acknowledgments: None}

\section{REFERENCES}

1. Huang C, Wang Y, Li X, Ren L, Zhao J, Hu Y, Zhang L, Fan G, Xu J, Gu X, Cheng Z. Clinical features of patients infected with 2019 novel coronavirus in Wuhan, China. The lancet. 2020 Feb 15;395(10223):497-506.

2. Ferrando C, Mellado-Artigas R, Gea A, Arruti E, Aldecoa C, Bordell A, Adalia R, Zattera L, Ramasco F, Monedero P, Maseda E. Patient characteristics, clinical course and factors associated to ICU mortality in critically ill patients infected with SARS-CoV-2 in Spain: a prospective, cohort, multicentre study. Revista
Española de Anestesiología y Reanimación (English Edition). 2020 Oct 1;67(8):425-37.

3. Rochwerg B, Granton D, Wang DX, Helviz Y, Einav S, Frat JP, Mekontso-Dessap A, Schreiber A, Azoulay E, Mercat A, Demoule A. High flow nasal cannula compared with conventional oxygen therapy for acute hypoxemic respiratory failure: a systematic review and meta-analysis. Intensive care medicine. 2019 May;45(5):563-72.

4. Chatila W, Nugent T, Vance G, Gaughan J, Criner GJ. The effectof high flow versus low flow oxygen on exercise in advanced obstructive airways disease. Chest. 2004;126(4):1108-15.

5. Shepard Jr JW, Burger CD. Nasal and oral flow volumes loopsin normal subjects and patients with obstructive sleep apnea.Am Rev Respir Dis. 1990;142(6 Pt 1):1288—93.

6. Parke R, McGuinness S, Eccleston M. Nasal highflow therapy delivers low level positive airway pressure. Br J Anaesth. 2009;103(6):886-90.

7. Groves N, Tobin A. High flow nasal oxygen generates positive airway pressure in adult volunteers. Aust Crit Care. 2007;20(4):126-31.

8. Calligaro GL, Lalla U, Audley G, Gina P, Miller MG, Mendelson M, Dlamini S, Wasserman S, Meintjes G, Peter J, Levin D. The utility of highflow nasal oxygen for severe COVID-19 pneumonia in a resource-constrained setting: A multi-centre prospective observational study. EClinicalMedicine. 2020 Nov 1;28:100570.

9. Xu Q, Wang T, Qin X, Jie Y, Zha L, Lu W. Early awake prone position combined with high-flow nasal oxygen therapy in severe COVID-19: a case series. Critical Care. 2020 Dec;24(1):1-3. 